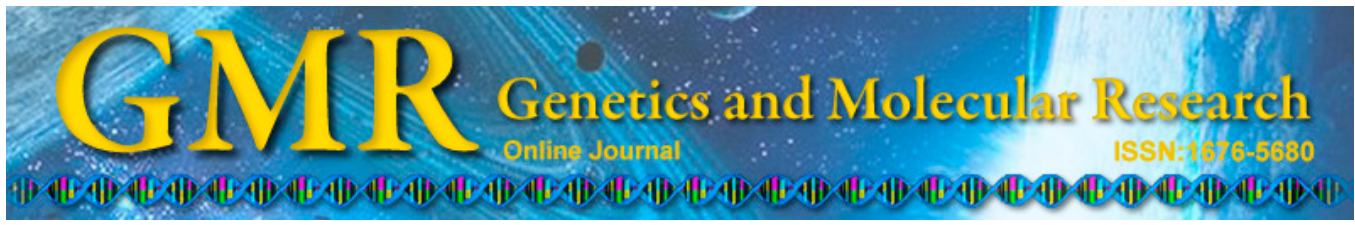

\title{
Cassava (Manihot esculenta Krantz) genome harbors $K N O X$ genes differentially expressed during storage root development
}

\author{
D. Guo ${ }^{1}$, H.L. Li ${ }^{1}$, X. Tang ${ }^{1,2}$ and S.Q. Peng ${ }^{1}$
}

${ }^{1}$ Key Laboratory of Biology and Genetic Resources of Tropical Crops, Ministry of Agriculture, Institute of Tropical Bioscience and Biotechnology, Chinese Academy of Tropical Agricultural Sciences, Haikou, China ${ }^{2}$ College of Agriculture, Hainan University, Haikou, China

Corresponding author: S.Q. Peng

E-mail: shqpeng@163.com

Genet. Mol. Res. 13 (4): 10714-10726 (2014)

Received November 4, 2013

Accepted April 27, 2014

Published December 18, 2014

DOI http://dx.doi.org/10.4238/2014.December.18.13

\begin{abstract}
In plants, homeodomain proteins play a critical role in regulating various aspects of plant growth and development. KNOX proteins are members of the homeodomain protein family. The KNOX transcription factors have been reported from Arabidopsis, rice, and other higher plants. The recent publication of the draft genome sequence of cassava (Manihot esculenta Krantz) has allowed a genome-wide search for M. esculenta KNOX (MeKNOX) transcription factors and the comparison of these positively identified proteins with their homologs in model plants. In the present study, we identified $12 \mathrm{MeKNOX}$ genes in the cassava genome and grouped them into two distinct subfamilies based on their domain composition and phylogenetic analysis. Furthermore, semi-quantitative reverse transcription polymerase chain reaction analysis was performed to elucidate the expression profiles of these genes in different tissues and during various stages of root development. The analysis of $M e K N O X$ expression profiles of indicated that $12 \mathrm{MeKNOX}$ genes display differential expressions either in their transcript abundance or
\end{abstract}


expression patterns.

Key words: KNOX transcription factor; Manihot esculenta; Differential expression; Storage root

\section{INTRODUCTION}

Homeodomain (HD) proteins constitute a large family of transcription factors with an HD DNA-binding domain at the N-terminus in eukaryotes. HD proteins play fundamental roles in a diverse set of plant developmental processes, from pattern formation to cell type specification (Gehring et al., 1994; Chan et al., 1998; Mukherjee et al., 2009). In plants, HD proteins can be classified into 14 distinct families based on the sequence similarity of HDs and their unique codomains (Mukherjee et al., 2009). KNOTTED1-like homeobox (KNOX) proteins are members of the HD protein family. KNOX genes encode atypical HD proteins that have three extra amino acids between helix 1 and helix 2 (Bertolino et al., 1995). Within the three amino acid loop extension (TALE) family of HDs, KNOX proteins are closely related to myeloid ecotropic viral integration site (MEIS) proteins in humans because of a conserved N-terminal region. This domain, called MEINOX after KNOX and MEIS (Bürglin, 1997), defines a subclass of the TALE family. The MEINOX domain can be divided into KNOX1 and KNOX2, and it may function in protein-protein interactions (Bürglin, 1997). KNOX genes fall into two classes (KNOX I and KNOX II) based on amino acid similarity within consensus domains, intron position, and expression patterns (Kerstetter et al., 1994; Reiser et al., 2000), and these classes are conserved among both dicots and monocots (Kerstetter et al., 1994; Bharathan et al., 1999; Mukherjee et al., 2009). Both KNOX families have a conserved diagnostic KNOX domain upstream of the HD that is composed of two blocks (KNOX A and KNOX B) separated by a variable region (Bürglin, 1997; Mukherjee et al., 2009), as well as a shorter motif adjacent to the HD, which is named ELK (Vollbrecht et al., 1991). KNOXI genes are required for stem cell maintenance, and they inhibit cell differentiation during organogenesis (Chan et al., 1998; Hake et al., 2004; Scofield and Murray, 2006; Jouannic et al., 2007; Hay and Tsiantis, 2009, 2010; Testone et al., 2009; Srinivasan et al., 2011). The different regulation of KNOXI in species with simple and compound leaves subtends the diversity of foliar shape (Bhatt et al., 2004; Hay and Tsiantis, 2009). KNOX II genes show a more widespread expression, and, although functional data are somewhat lacking, they may have a yet undefined function in development (Serikawa et al., 1997; Di Giacomo et al., 2008). Studies on Arabidopsis KNOX II functions (KNAT3, KNAT4, KNAT5, and KNAT7) have been limited (Truernit et al., 2006; Pagnussat et al., 2007). The expression patterns of Arabidopsis KNAT3 were profiled in aerial organs (Serikawa et al., 1997) and roots, together with those of KNAT4 and 5 (Truernit et al., 2006). Cytokinin (Truernit et al., 2006; Soucek et al., 2007; Di Giacomo et al., 2008), abscisic acid, and gibberellins (Morère-Le Paven et al., 2007) affect class II KNOX transcription in distinct organs. More recently, the function of the KNOX gene family has been expanded to include additional roles in lateral organ development (Tanaka et al., 2008; Hay and Tsiantis, 2010).

Cassava (Manihot esculenta Krantz) is a tropical crop that stores important quantities of starch in its roots. The high starch content (20-40\%) makes cassava a desirable energy source both for human consumption and industrial biofuel applications (Balat and Balat, 2009; Schmitz and Kavallari, 2009). Because of its wide ecological potential and tolerance to abiotic stress, cassava is cultivated throughout tropical Africa, Asia, and Americas. The 
genome of cassava is approximately $770 \mathrm{Mb}$ (Awoleye et al., 1994), and the draft genome sequence of cassava was obtained by a whole genome shotgun strategy. The cassava genome is predicted to contain 30,666 genes (Prochnik et al., 2012). However, the function of most of the genes remains unclear. This study identifies 12 members of the KNOX protein family in cassava based on publicly available sequence information. In addition, their phylogenetic relationships and expression analysis in plant development are described.

\section{MATERIAL AND METHODS}

\section{Database search and sequence retrieval}

Using the keyword search tool, sequences of cassava, Arabidopsis, rice, maize, grape, castor bean, Populus, and Medicago KNOX proteins were downloaded from Phytozome (http://www.phytozome.net/) through the keyword search of KNOX (PF03790, PF03791) and homeobox domain (PF00046). For the misannotated genes, manual reannotation was performed using the online web server FGENESH (http://linux1.softberry.com/berry.phtml). Then, all the sequences were further manually analyzed to confirm the presence of KNOX and homeobox domains using InterProScan (http://www.ebi.ac.uk/Tools/InterProScan/).

\section{Phylogenetic analysis}

All the candidate KNOX sequences were aligned using ClustalW and checked manually to exclude potentially redundant genes (Thompson et al., 1994), and all the non-redundant $K N O X$ genes were used for further analysis. Analyses of phylogenetic relationships were conducted using the MEGA 5.0 with the neighbor-joining method. Bootstrap analysis was performed using 1000 replicates with the pairwise deletion option. The phylogenetic trees were displayed using the MEGA 5.0 with a 50\% threshold branch value (Tamura et al., 2011).

\section{Gene structure analysis}

The exon/intron organization for individual $K N O X$ genes was illustrated with the Gene Structure Display Server (http://gsds.cbi.pku.edu.cn/) by aligning the cDNAs with their corresponding genomic DNA sequences from Phytozome (http://www.phytozome.net/poplar, release 2.1) (Guo et al., 2007).

\section{Identification of conserved motifs}

The program MEME (v4.8.1) (http://meme.sdsc.edu/meme/cgi-bin/meme.cgi) was used for the elucidation of motifs in 12 cassava KNOX protein sequences (Bailey and Elkan, 1995). Parameters were set as follows: optimum motif width set to $\geq 6$ and $\leq 200$; maximum number of motifs set to 20 .

\section{Plant material}

Cassava (cassava cultivar Huanan 8) plantlets were sterilized with 1\% sodium hypochlorite solution, and the plantlets were transferred to glass pots with Murashige and Skoog 
(MS) medium, $\mathrm{pH}$ 5.8. After cutting about 2-3 $\mathrm{cm}$ from the shoot tip of the cassava, shoot cuttings were transferred to a glass pot with MS medium and grown under 16-h illumination at $28^{\circ} \mathrm{C}$. The roots were formed from the sections of the shoot cuttings, and the plantlets were grown until they were approximately $10 \mathrm{~cm}$ high during 1.5 months, and then they were used as experimental material. The seedlings were harvested, immediately frozen in liquid nitrogen, and stored at $-80^{\circ} \mathrm{C}$ until the RNA preparation. Fibrous roots, intermediate roots, and storage roots were collected from one plantlet 4 months after growing under the natural conditions.

\section{RNA extraction}

Total RNA was extracted according to Li's method (Li et al., 2011). The quality and concentration of the extracted RNA were checked by agarose gel electrophoresis and measured by a spectrophotometer (DU-70, Beckman, USA). The total RNA extracts were treated with RNase-free DNase I (Fermentas, Shenzhen City, Guangdong, China) to completely remove genomic DNA. The extracted total RNA was stored at $-80^{\circ} \mathrm{C}$ until further use.

\section{Reverse transcription polymerase chain reaction (RT-PCR) and amplification of MeKNOX genes}

Total RNA $(8 \mu \mathrm{g})$ from cassava seedlings was used for reverse transcription using an oligo-dT primer. The cDNA was diluted 150 -fold. Diluted template $(1 \mu \mathrm{L})$, was amplified using MeKNOX-specific primers (Table 1). To establish whether MeKNOX4, MeKNOX6, and MeKNOX10 were expressed in cassava, 1, 3, and $5 \mu \mathrm{L}$ diluted template, and 1 and 2.5 $\mu \mathrm{L}$ undiluted cDNA were amplified using MeKNOX4-, MeKNOX6-, and MeKNOX10-specific primers. PCR analysis of the $M e K N O X$ genes was carried out with 40 cycles of programmed temperature control of $15 \mathrm{~s}$ at $95^{\circ} \mathrm{C}, 30 \mathrm{~s}$ at $57^{\circ} \mathrm{C}$, and $45 \mathrm{~s}$ at $72^{\circ} \mathrm{C}$ with a 3 -min preheat at $95^{\circ} \mathrm{C}$ and a 5 -min final extension at $72^{\circ} \mathrm{C}$. The actin gene was amplified as an internal control in the reactions with the actin-specific primers AF (5'-CAGTGGTCGACAACTGGTAT-3') and AR (5'-ATCCTCCAATCCAGACACTGT-3'). The PCR products were analyzed by $1.5 \%$ agarose gel electrophoresis with ethidium bromide staining.

\section{Semi-quantitative RT-PCR analysis}

RT-PCR for the analysis of $M e K N O X$ gene expressions was performed using total RNA from cassava tissues that was amplified using primers specific for MeKNOX genes (Table 1). Three independent RT-PCR were carried out to amplify MeKNOX genes and actin as a constitutive control that was also used to normalize the data. The cycling conditions were as follows: $95^{\circ} \mathrm{C}$ for $10 \mathrm{~min}$ and 35 cycles at $95^{\circ} \mathrm{C}$ for $30 \mathrm{~s}, 57^{\circ} \mathrm{C}$ for $30 \mathrm{~s}$, and $72^{\circ} \mathrm{C}$ for $45 \mathrm{~s}$. The PCR products were analyzed by $1.5 \%$ agarose gel electrophoresis with ethidium bromide staining.

\section{RESULTS}

\section{Identification of the KNOX gene family in cassava}

To identify putative $K N O X$ genes in cassava, sequences of cassava KNOX proteins were downloaded from Phytozome (http://www.phytozome.net/) using the key word search of KNOX 
(PF03790, PF03791) and homeobox domain (PF00046). Through this approach, 12 KNOX gene sequences were identified. To confirm the putative $K N O X$ genes in the cassava genome, the amino acid sequences of all 12 proteins were searched for the presence of HD and KNOX domain by Pfam and SMART. As a result of our extensive search for $K N O X$ genes, 12 non-redundant $K N O X$ genes (named MeKNOX1 to MeKNOX12) were confirmed from the original data. All KNOX candidates were manually analyzed using the InterProScan (http://www.ebi.ac.uk/Tools/ Inter-ProScan/) to verify the presence of HD and KNOX domain. The KNOX genes identified in cassava encode proteins ranging from 245 to 431 amino acids in length (Table 1), with an average of 345 amino acids. The full-length cDNAs of the $12 \mathrm{KNOX}$ genes were cloned and sequenced.

\begin{tabular}{|c|c|c|c|c|c|}
\hline Locus name & Gene name & Protein length & Expressed* & $\mathrm{CDS}^{* *}$ & Specific primers for RT-PCR \\
\hline Mes023294 & MeKNOX1 & 430 aa & + & + & $\begin{array}{l}\text { F: 5'-ATCCCTGCAAAGCTTAACAG-3' } \\
\text { R: 5'-TCAGTTCATGCCTCACTCTT-3' }\end{array}$ \\
\hline Mes008073 & MeKNOX2 & 431 aа & + & + & $\begin{array}{l}\text { F: 5'-GAGGGTGAGGCAAGAACTGA-3' } \\
\text { R: 5'-TGTGCCAGTTTCTCTTCCGC-3' }\end{array}$ \\
\hline Mes011208 & MeKNOX3 & 340 aa & + & + & $\begin{array}{l}\text { F: 5'-ACTCCGTGCTTGGAAATGGC-3' } \\
\text { R: 5'-TGATCTCTCAGTTTCAGTGG-3' }\end{array}$ \\
\hline Mes011212 & MeKNOX4 & 340 aа & + & + & $\begin{array}{l}\text { F: 5'-TCCTCACTGAAAGTGAGAAG-3' } \\
\text { R: 5'-GATACGGCCACTTTGAATGT-3' }\end{array}$ \\
\hline Mes024801 & MeKNOX5 & 294 aа & + & + & $\begin{array}{l}\text { F: 5'-AAAAAGAAGGGCTGGAAAGC-3' } \\
\text { R: 5'-AGATGTCGCGGATTGAGAGT-3' }\end{array}$ \\
\hline Mes010084 & MeKNOX6 & 368 aa & + & + & $\begin{array}{l}\text { F: 5'-TCCGAGGAAGATCAGGAGAA-3' } \\
\text { R: 5'-CTGCACTCTGTGGATGGAGA-3' }\end{array}$ \\
\hline Mes021989 & MeKNOX7 & 346 aa & + & + & $\begin{array}{l}\text { F: 5'-GCAAGTACAGTGGGTATTTA-3' } \\
\text { R: 5'-AGTGAGAGATATCCATTGGA-3' }\end{array}$ \\
\hline Mes010444 & MeKNOX8 & 360 aа & + & + & $\begin{array}{l}\text { F: 5'-TCATCATCACCCTCCTCCTC-3' } \\
\text { R: 5'-TGCTGCAGAAGCACAGGCAT-3' }\end{array}$ \\
\hline Mes014822 & MeKNOX9 & 245 aa & + & + & $\begin{array}{l}\text { F: 5'-GCGCATCAAGCACTTAATCA-3' } \\
\text { R: 5'-GTTCTGGGTCCTTCGAGGTG-3' }\end{array}$ \\
\hline Mes011535 & MeKNOX10 & 332 aа & + & + & $\begin{array}{l}\text { F: 5'-CAAAGGATGCGAGGATGATT-3' } \\
\text { R: 5'-CСТCTCTACCTCCACCACCA-3' }\end{array}$ \\
\hline Mes011625 & MeKNOX11 & 330 aа & + & + & $\begin{array}{l}\text { F: 5'-GTGGGGTTGGTTCAGAAGAG-3' } \\
\text { R: 5'-ACCCAAGCAAGAAGGAACAA-3' }\end{array}$ \\
\hline Mes026974 & MeKNOX12 & 343 aа & + & + & $\begin{array}{l}\text { F: 5'-GGAGTTGAGTGGAGGGGAAT-3' } \\
\text { R: 5'-TCCAGTTGAGTCTGCCAGTG-3' }\end{array}$ \\
\hline
\end{tabular}

*The expression of $K N O X$ genes was detected in a variety of cassava tissues by reverse transcription polymerase chain reaction (RT-PCR). $(+)=$ expressed $K N O X$ genes. ${ }^{* *}$ The conserved domain sequence (CDS) of KNOX genes was obtained by RT-PCR. $(+)=$ obtained.

To establish whether the $K N O X$ genes were expressed, RT-PCR analysis was performed with primers based on the sequences of the 12 genes in cassava. Twelve putative $K N O X$ genes were expressed in cassava seedling tissues, but among the 12 putative $K N O X$ genes, the expression of $K N O X 4, K N O X 6$, and $K N O X 10$ was very weak (Figure 1).

\section{Phylogenetic analysis of the $K N O X$ gene family}

From the multiple sequence alignments of full-length MeKNOX proteins, distinctive motifs were found to be conserved (Figure 2). The predicted protein sequences of all the MeKNOX genes were used to generate a phylogenetic tree. The tree categorized the MeKNOX genes into two major groups (class I and II) with well-supported bootstrap values (Figure 3). We subsequently performed an exon-intron structure analysis to support the phylogeny reconstruction (Figure 3). The $K N O X$ genes within the same groups of the phylogenetic tree all showed similar exon-intron 
structures, consensus domains, and intron positions. The schematic structures revealed that each coding sequence of the $M e K N O X$ genes is disrupted by two or more introns.

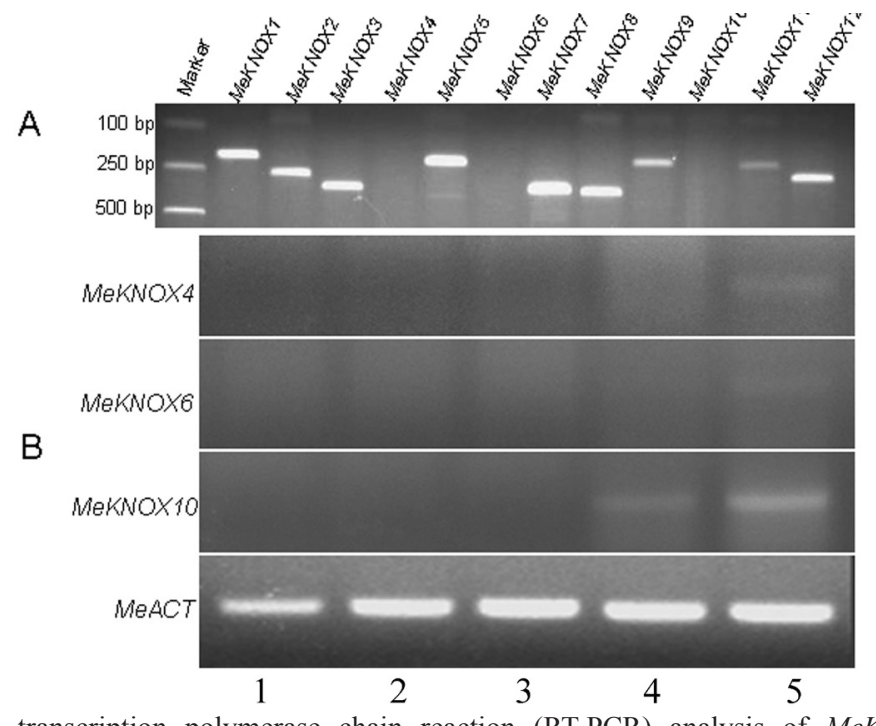

Figure 1. Reverse transcription polymerase chain reaction (RT-PCR) analysis of MeKNOX genes. Total RNA was isolated from cassava seedlings. Total RNA $(8 \mu \mathrm{g})$ was reverse transcribed. The cDNA was diluted 150 -fold. A. Diluted template $(1 \mu \mathrm{L})$ was PCR-amplified using primers specific for MeKNOX genes. B. PCR analysis of MeKNOX4, MeKNOX6, and MeKNOX10. Lanes 1-3 =1,3, and $5 \mu \mathrm{L}$ diluted cDNA, respectively, were used as template. Lanes $4-5=1$ and $2.5 \mu \mathrm{L}$ undiluted cDNA were used as the template and amplified using MeKNOX4-, MeKNOX6-, and MeKNOX10-specific primers. The MeACT was used as an internal control parallel in the reactions, amplified with $M e A C T$ specific primers AF (5'-CAGTGGCCGTACAACAGGTAT-3') and AR (5'-ATCCTCCAATCCAGACACTGT-3').

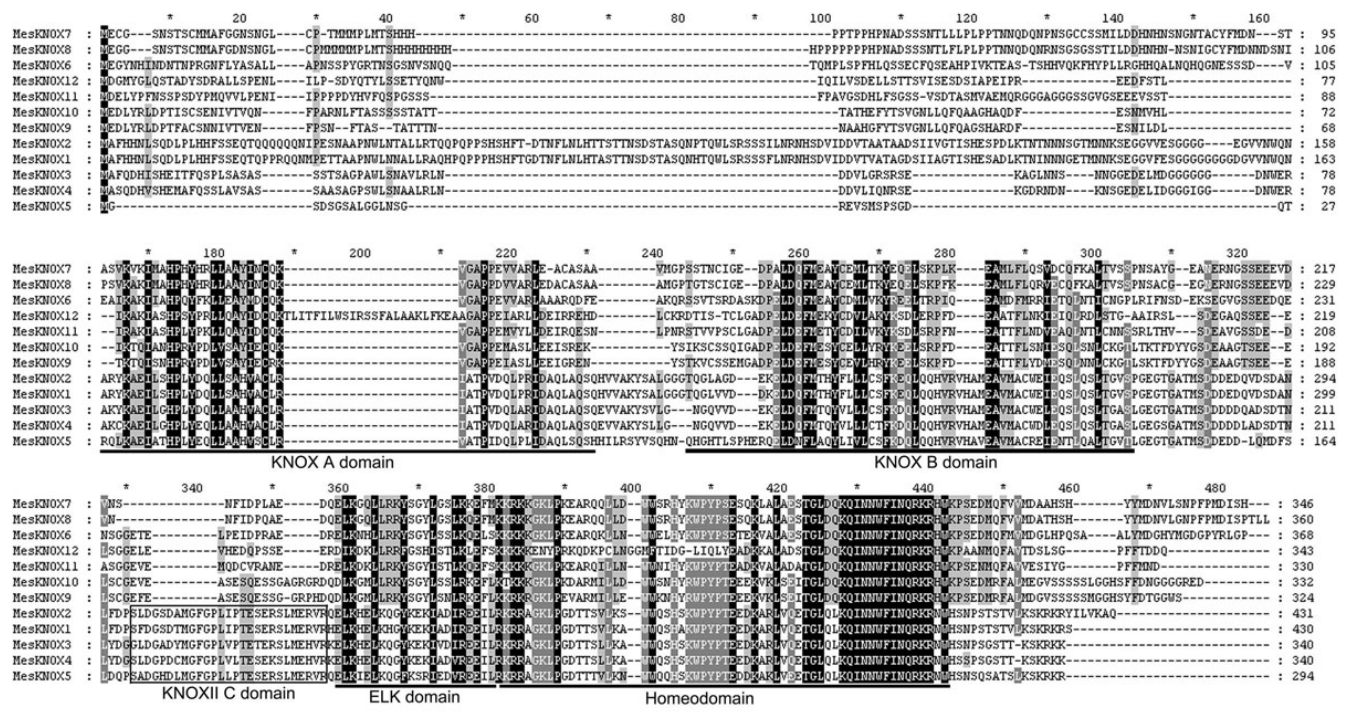

Figure 2. Characterization of cassava KNOX protein. Multiple sequence alignment of MeKNOX proteins. The conserved amino acids of different physicochemical properties are highlighted in different shades of gray. 
A

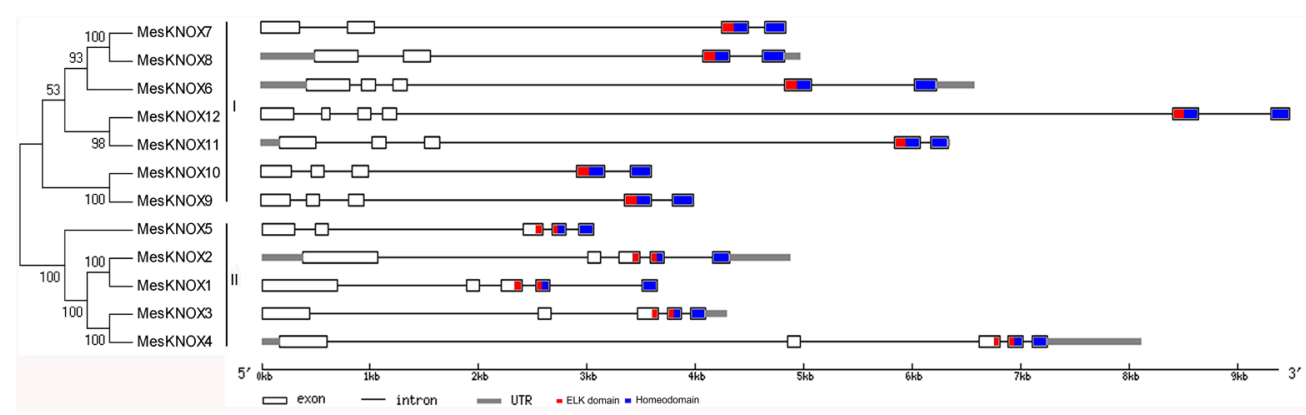

B

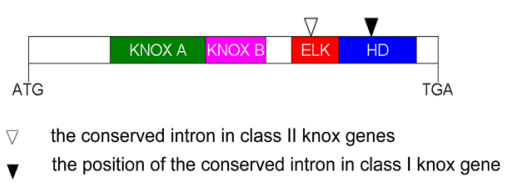

Figure 3. Phylogenetic relationship and gene structure of the 12 predicted cassava KNOX proteins. A. Neighborjoining tree (left): the unrooted tree was generated with the MEGA 5.0 using the full-length amino acid sequences of the 12 predicted cassava KNOX proteins. The bootstrap values are indicated at the branches in black numbers, and the proteins were named according to their gene codes (see Table 1). Gene structure (right): exons and introns are indicated by boxes and thin gray lines, respectively. Thick gray lines represent the untranslated regions (UTRs). The length of each $K N O X$ gene can be estimated using the scale at the bottom. B. Different position of the conserved intron between in class I KNOX gene and in class KNOXII.

To examine the phylogenetic relationships of $K N O X$ genes from different species, a combined phylogenetic tree was constructed from an alignment of the full-length sequences of cassava, maize, rice, grape, castor bean, Populus, Medicago, and Arabidopsis KNOX proteins (Figure 4). The results showed that MeKNOX proteins can be assigned to STM-like class I (MeKNOX7 and MeKNOX8), KNAT1/BP-like class I (MeKNOX6), KNAT2/6-like class I (MeKNOX9, MeKNOX10, MeKNOX11, and MeKNOX12), and class II (MeKNOX1, MeKNOX2, MeKNOX3, MeKNOX4, and MeKNOX5).

\section{Gene structure and conserved motifs of cassava $K N O X$ genes}

Twenty conserved motifs were identified in the cassava KNOX proteins using the MEME web server (Figure 5). Each of the putative motifs obtained from MEME was annotated by searching Pfam and SMART. Based on the distribution of the 20 predicted motifs, the 12 cassava KNOX genes were divided into two classes, which was completely consistent with the classifications from the phylogenetic analysis. Motifs 1 and 2, encoding the HD, were found in all $12 \mathrm{MeKNOX}$ genes. The conserved motif 10 was identified in the KNOX1 protein, while motifs 6 and 18 were identified in the KNOX2 protein. In addition, some specific motifs with unknown functions were also found, indicating that these motifs are likely required for specific functions. The detailed information about the conserved amino acid sequences and lengths of the 20 motifs are shown in Table 2. 


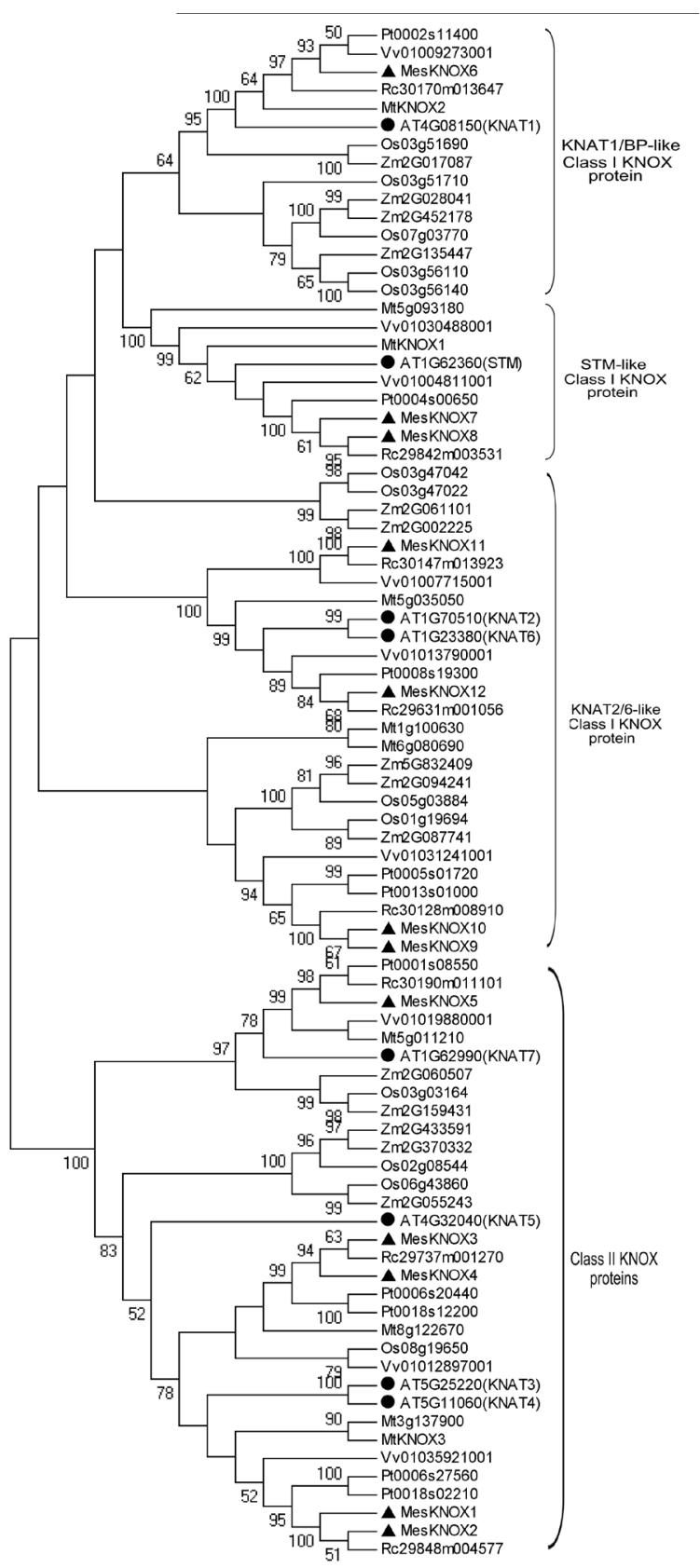

Figure 4. Phylogenetic relationships of cassava KNOX proteins and other KNOX proteins from different species. The minimum evolution method was used for phylogenetic analyses by the MEGA 5.0. Cassava KNOX proteins and the putative Arabidopsis orthologs are indicated by triangles and circles, respectively. Sequences of cassava, Arabidopsis, rice, maize, grape, castor bean, Populus, and Medicago KNOX proteins were downloaded from Phytozome (http://www.phytozome.net/) using the key word search of KNOX (PF03790, PF03791) and homeobox domain (PF00046). 


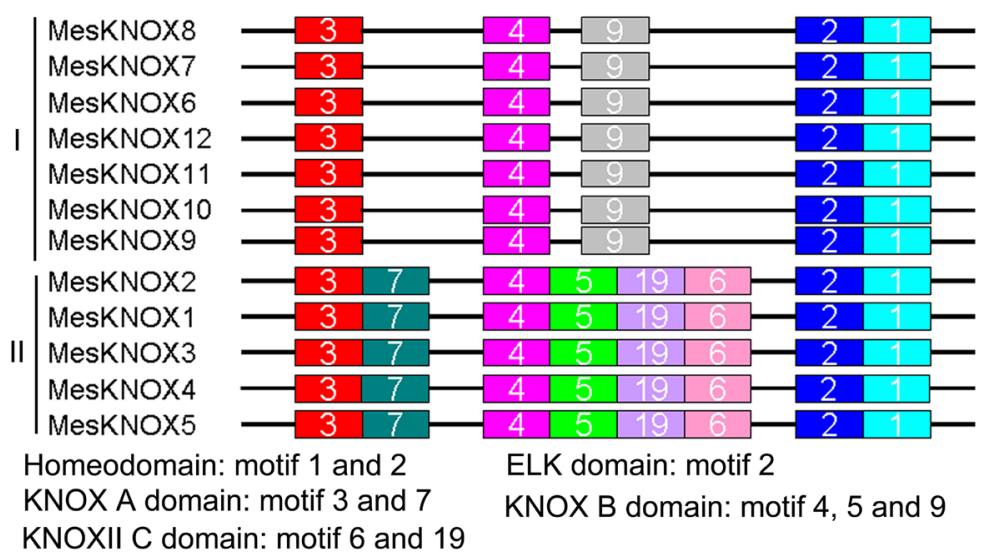

Figure 5. Distribution of 20 putative conserved motifs in MeKNOX proteins. Motifs of KNOX proteins were identified by the MEME web server. Note that the length of each box in the proteins does not represent the actual motif size, and the colored boxes were ordered manually according to the results of the MEME analysis. The conserved amino acid sequences and length of each motif are shown in Table 2.

Table 2. MEME motif sequences in cassava KNOX proteins.

\begin{tabular}{rcl}
\hline Motif No. & Size (a) & Conserved amino acid sequence \\
\hline 1 & 56 & ELKRKYKGYIADIREEFLRKRRKGKLPKDTRQILKNWWQRHYKWPYPTEEDKVRLV \\
2 & 29 & TGLDQKQINNWFINQRKRHWHPNPDMQFV \\
3 & 41 & IKAKIMAHPLYPQLLAAYIACQKVGTPPDQVARIDAICAQS \\
4 & 29 & PELDQFMEHYCEMLCKYKEQLQRPFRVHM \\
5 & 41 & MEAVMACWEIEQSLQSLTGVSPGEGTGATMSDDDDDQVDSD \\
6 & 29 & DPDCMGFGPLIPTESERSLMERVRQELKH \\
7 & 80 & MESPDLKTNINNNGGTMNNK \\
& & MAFHHNLSQDLPLHHFSSEQTQPPRQQNIPETNAAPNWLNNALLRTQQPQPPPHSHF \\
8 & 57 & QHVVCQYNALCNGTV \\
9 & 15 & MMMPDEAAGSSEEEVSCGEFE \\
10 & 21 & MAFQDHISHEITFQSPLAVSASSATSAGPAWLSNAVLRLNDDVLIRNRSEKGGRNDNK \\
11 & 57 & NGGEDELIDGGGIGGDNWERAK \\
12 & 80 & MMDATHSHYYMDNVLGNPFPM \\
13 & 21 & CGSLYRLDPTFACSENIVTVQNFP \\
14 & 24 & HGFYTSVGNLLQFQAGGHARDFESNI \\
15 & 21 & CYFMDN \\
16 & 26 & KSKRKR \\
17 & 6 & MVGWQNAR \\
18 & 6 &
\end{tabular}

\section{Differential expression profile of $M e K N O X$ genes in different cassava organs}

Semi-quantitative RT-PCR was used to analyze the different organs of cassava seedlings (Figure 6A) to investigate if the transcript levels of the MeKNOX genes varied during plant development. MeKNOX genes displayed differential expression either in their transcript abundance or expression patterns in cassava seedlings (Figure 6B). The expression profiles revealed spatial variations in the expression of MeKNOX genes of different cassava organs. The expression levels of MeKNOX1, $-2,-3,-5,-7$, and -8 were significantly higher in the 


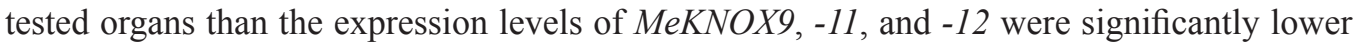
in the in the tested organs. By contrast, such genes as MeKNOX4, -6 , and -10 were almost not expressed in all investigated tissues. Some genes, such as MeKNOX1, -2, -3, -5, -7, -8, and -12 were expressed in all investigated tissues but difference in the expression levels of different organs. MeKNOX9 was expressed in leaves, stem, but not in root. MeKNOX4 was in root, stem, but not in leaves. Furthermore, the transcript levels of MeKNOX genes in the same organ show temporal variations. For example, MeKNOX1, MeKNOX2, and MeKNOX3 were expressed more in the leaves than in other organs, MeKNOX7 and MeKNOX8 were expressed more in the stem than in other organs, and MeKNOX9 was not detected in the root.

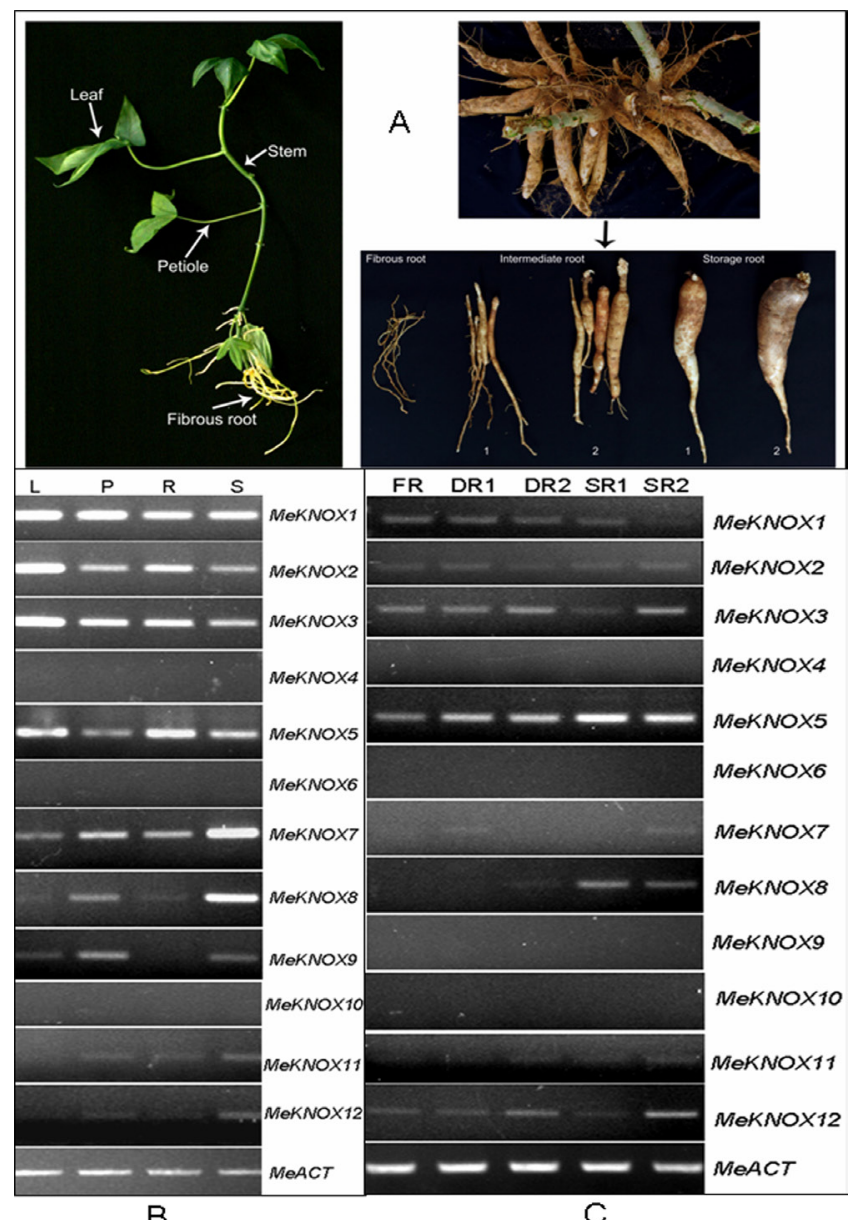

Figure 6. Reverse transcription polymerase chain reaction (RT-PCR) analysis of MeKNOX gene expression profiles. A. The cassava seedling and the roots were defined as follows: fibrous roots (FR, less than $0.5 \mathrm{~cm}$ in diameter), intermediate roots (DR1, 0.5-1 cm in diameter; DR2, 2-3 cm in diameter), and storage roots (SR1, 3-5 $\mathrm{cm}$ in diameter; SR2, greater than $5 \mathrm{~cm}$ in diameter). B. Expressions of MeKNOX genes in different plant organs. C. Expressions of MeKNOX genes during storage root development. Total RNA that was used as the template for RT-PCR was isolated from young leaves $(\mathrm{L})$, petioles $(\mathrm{P})$, roots $(\mathrm{R})$, and stems $(\mathrm{S})$. The expression of the actin gene was used as a control. 


\section{Differential expression profiles of $M e K N O X$ genes during cassava storage root development}

Our study of gene expression during storage root development provided important information about storage root formation and starch accumulation, and it unlocked new traits to improve starch yield (Sojikul et al., 2010). In order to study the MeKNOX genes transcription patterns during cassava storage root development (Figure 6A), total RNA was isolated from stages of storage root development and subjected to semi-quantitative RT-PCR analysis. The expression levels of MeKNOX5 and MeKNOX8 increased during storage root development, whereas the expression level of $M e K N O X 1$ decreased during storage root development. The expression of MeKNOX2, MeKNOX3, MeKNOX10, MeKNOX11, and MeKNOX12 seemed almost constitutive, but it was decreased slightly during storage root development. MeKNOX4, MeKNOX6, $M e K N O X 9$, and MeKNOX10 were not expressed during storage root development (Figure 6C).

\section{DISCUSSION}

This study presents the annotation of 12 members of the KNOX gene subfamily in cassava based on publicly available sequence information and classifies them according to KNOX classes I and II. The total number of KNOX genes that were identified in cassava (12) is a little greater than that in Arabidopsis (8), grape (9), castor bean (8), poplar (10), and Medicago (10).

Despite the identification or prediction of $K N O X$ genes from different species, only a small number has been functionally characterized (Li et al., 2012). Class I genes are typically expressed in meristem-enriched tissues and not in leaves, whereas class II genes are expressed in all organs (Hay and Tsiantis, 2009, 2010). Generally, class I KNOX transcription factors are important regulators of shoot apical meristem function and leaf morphology because they contribute to dissected leaf development (Hake et al., 2004; Jouannic et al., 2007; Barth et al., 2009). Moreover, tuber development was enhanced in transgenic potato plants overexpressing the KNOXI gene POTHI (Rosin et al., 2003). There is much evidence that KNOXI genes also function in root development. Scanlon et al. (2002) observed that increased KNOXI gene expression that was caused by semaphore 1 mutation led to decreased development of lateral roots. Dean et al. (2004) reported that the downregulation of an Arabidopsis KNOX I gene, KNAT6, was associated with an increased number of lateral roots. Weak expression of $K N O X$ $I$ genes in root tissue was also observed in Arabidopsis (Truernit et al., 2006), tomato (Koltai and Bird, 2000), maize (Kerstetter et al., 1994), and two Papaveraceae plants (Groot et al., 2005), or it was limited to a specific tissue, such as the lateral root primordium (Dean et al., 2004; Truernit et al., 2006). More importantly, the expression of KNOXI genes in sweet potato during the secondary growth of root tissue was reported (Tanaka et al., 2008).

The expression levels of all MeKNOX genes in four different tissues, leaves, petiole, roots, and stems, were analyzed. The expression profiles revealed spatial and temporal variations in the expression of MeKNOX genes in different cassava organs. MeKNOX5 and $M e K N O X 8$ expression increased during storage root development, which indicated that $\mathrm{Me}$ KNOX5 and MeKNOX8 could play a role in the development of the plant root. The MeKNOX1, $M e K N O X 2$, and $M e K N O X 3$ expression levels were significantly higher in the leaves than in the other organs, indicating that MeKNOX1, MeKNOX2, and MeKNOX3 play key roles in the leaf development. The expression levels of MeKNOX7 and MeKNOX8 were significantly 
higher in the stem than in other organs. Hence, these genes may play regulatory roles in stem development. In addition, other MeKNOX genes, such as MeKNOX5 and MeKNOX7, showed relatively high expression levels in all four organs. Tanaka et al. (2008) identified three different KNOXI genes (ibkn1,ibkn2, and $i b k n 3)$ in sweet potato storage roots. These genes are involved in the development of sweet potato storage roots (Tanaka et al., 2008). Thus, the highly expressed MeKNOX genes or differentially expressed MeKNOX genes reported in this study may play regulatory roles in cassava development. However, more research is needed to determine the functions of the MeKNOX genes.

\section{ACKNOWLEDGMENTS} (\#2010CB126603).

\section{REFERENCES}

Awoleye F, van Duren M, Dolezel J and Novak FJ (1994). Nuclear DNA content and in vitro induced somatic polyploidization cassava (Manihot esculenta Crantz) breeding. Euphytica 76: 195-202.

Bailey TL and Elkan C (1995). The value of prior knowledge in discovering motifs with MEME. Proc. Int. Conf. Intell. Syst. Mol. Biol. 3: 21-29.

Balat $\mathrm{M}$ and Balat H (2009). Recent trends in global production and utilization of bio-ethanol fuel. Appl. Energy 86: 2273-2282.

Barth S, Geier T, Eimert K, Watillon B, et al. (2009). KNOX overexpression in transgenic Kohleria (Gesneriaceae) prolongs the activity of proximal leaf blastozones and drastically alters segment fate. Planta 230: 1081-1091.

Bertolino E, Reimund B, Wildt-Perinic D and Clerc RG (1995). A novel homeobox protein, which recognizes a TGT core and functionally interferes with a retinoid-responsive motif. J. Biol. Chem. 270: 31178-31188.

Bharathan G, Janssen BJ, Kellogg EA and Sinha N (1999). Phylogenetic relationships and evolution of the KNOTTED class of plant homeodomain proteins. Mol. Biol. Evol. 16: 553-563.

Bhatt AM, Etchells JP, Canales C, Lagodienko A, et al. (2004). VAAMANA-a BEL1-like homeodomain protein, interacts with KNOX proteins BP and STM and regulates inflorescence stem growth in Arabidopsis. Gene 328: 103-111.

Bürglin TR (1997). Analysis of TALE superclass homeobox genes (MEIS, PBC, KNOX, Iroquois, TGIF) reveals a novel domain conserved between plants and animals. Nucleic Acids Res. 25: 4173-4180.

Chan RL, Gago GM, Palena CM and Gonzalez DH (1998). Homeoboxes in plant development. Biochim. Biophys. Acta 1442: 1-19.

Dean G, Casson S and Lindsey K (2004). KNAT6 gene of Arabidopsis is expressed in roots and is required for correct lateral root formation. Plant Mol. Biol. 54: 71-84.

Di Giacomo E, Sestili F, Iannelli MA, Testone G, et al. (2008). Characterization of KNOX genes in Medicago truncatula. Plant Mol. Biol. 67: 135-150.

Gehring WJ, Qian YQ, Billeter M, Furukubo-Tokunaga K, et al. (1994). Homeodomain-DNA recognition. Cell 78: 211223.

Groot EP, Sinha N and Gleissberg S (2005). Expression patterns of STM-like KNOX and Histone H4 genes in shoot development of the dissected-leaved basal eudicot plants Chelidonium majus and Eschscholzia californica (Papaveraceae). Plant Mol. Biol. 58: 317-331.

Guo AY, Zhu QH, Chen X and Luo JC (2007). GSDS: a gene structure display server. Yi Chuan 29: 1023-1026.

Hake S, Smith HMS, Holtan H, Magnani E, et al. (2004). The role of KNOX genes in plant development. Annu Rev. Cell Dev. Biol. 20: 125-151.

Hay A and Tsiantis M (2009). A KNOX family TALE. Curr. Opin. Plant Biol. 12: 593-598.

Hay A and Tsiantis M (2010). KNOX genes: versatile regulators of plant development and diversity. Development 137: 3153-3165.

Jouannic S, Collin M, Vidal B, Verdeil JL, et al. (2007). A class I KNOX gene from the palm species Elaeis guineensis (Arecaceae) is associated with meristem function and a distinct mode of leaf dissection. New Phytol. 174: 551-568.

Kerstetter R, Vollbrecht E, Lowe B, Veit B, et al. (1994). Sequence analysis and expression patterns divide the maize 
knotted1-like homeobox genes into two classes. Plant Cell 6: 1877-1887.

Koltai H and Bird DM (2000). Epistatic repression of PHANTASTICA and class 1 KNOTTED genes is uncoupled in tomato. Plant J. 22: 455-459.

Li FZ, Yang SX, Wu CX, Wei HC, et al. (2012). Structure and expression analysis of KNOX gene family in soybean. Chin. Bul. Bot. 47: 236-247.

Li HL, Wang Y, Guo D, Tian WM, et al. (2011). Three MADS-box genes of Hevea brasiliensis expressed during somatic embryogenesis and in the laticifer cells. Mol. Biol. Rep. 38: 4045-4052.

Morère-Le Paven MC, Anzala F, Recton A and Limami AM (2007). Differential transcription initiation and alternative RNA splicing of Knox7, a class 2 homeobox gene of maize. Gene 401: 71-79.

Mukherjee K, Brocchieri L and Bürglin TR (2009). A comprehensive classification and evolutionary analysis of plant homeobox genes. Mol. Biol. Evol. 26: 2775-2794.

Pagnussat GC, Yu HJ and Sundaresan V (2007). Cell-fate switch of synergid to egg cell in Arabidopsis eostre mutant embryo sacs arises from misexpression of the BEL1-like homeodomain gene BLH1. Plant Cell 19: 3578-3592.

Prochnik S, Marri PR, Desany B, Rabinowicz PD, et al. (2012). The cassava genome: current progress, future directions. Trop. Plant Biol. 5: 88-94.

Reiser L, Sánchez-Baracaldo P and Hake S (2000). Knots in the family tree: evolutionary relationships and functions of knox homeobox genes. Plant Mol. Biol. 42: 151-166.

Rosin FM, Hart JK, Horner HT, Davies PJ, et al. (2003). Overexpression of a Knotted-like homeobox gene of potato alters vegetative development by decreasing gibberellin accumulation. Plant Physiol. 132: 106-117.

Scanlon MJ, Henderson DC and Bernstein B (2002). SEMAPHORE1 functions during the regulation of ancestrally duplicated knox genes and polar auxin transport in maize. Development 129: 2663-2673.

Schmitz PM and Kavallari A (2009). Crop plants versus energy plants - on the international food crisis. Bioorg. Med. Chem. 17: 4020-4021.

Scofield S and Murray JA (2006). KNOX gene function in plant stem cell niches. Plant Mol. Biol. 60: 929-946.

Serikawa KA, Martinez-Laborda A, Kim HS and Zambryski PC (1997). Localization of expression of KNAT3, a class 2 knottedl-like gene. Plant J. 11: 853-861.

Sojikul P, Kongsawadworakul P, Viboonjun U, Thaiprasit J, et al. (2010). AFLP-based transcript profiling for cassava genome-wide expression analysis in the onset of storage root formation. Physiol. Plant 140: 189-198.

Soucek P, Klíma P, Reková A and Brzobohatý B (2007). Involvement of hormones and KNOXI genes in early Arabidopsis seedling development. J. Exp. Bot. 58: 3797-3810.

Srinivasan C, Liu Z and Scorza R (2011). Ectopic expression of class 1 KNOX genes induce adventitious shoot regeneration and alter growth and development of tobacco (Nicotiana tabacum L) and European plum (Prunus domestica L). Plant Cell Rep. 30: 655-664.

Tamura K, Peterson D, Peterson N, Stecher G, et al. (2011). MEGA5: molecular evolutionary genetics analysis using maximum likelihood, evolutionary distance, and maximum parsimony methods. Mol. Biol. Evol. 10: 2731-2739.

Tanaka M, Kato N, Nakayama H, Nakatani M, et al. (2008). Expression of class I knotted1-like homeobox genes in the storage roots of sweet potato (Ipomoea batatas). J. Plant Physiol. 165: 1726-1735.

Testone G, Condello E, Verde I, Caboni E, et al. (2009). The peach (Prunus persica [L.] Batsch) homeobox gene KNOPE3, which encodes a class 2 knotted-like transcription factor, is regulated during leaf development and triggered by sugars. Mol. Genet. Genomics 282: 47-64.

Thompson JD, Higgins DG and Gibson TJ (1994). CLUSTAL W: improving the sensitivity of progressive multiple sequence alignment through sequence weighting, position-specific gap penalties and weight matrix choice. Nucleic Acids Res. 22: 4673-4680.

Truernit E, Siemering KR, Hodge S, Grbic V, et al. (2006). A map of KNAT gene expression in the Arabidopsis root. Plant Mol. Biol. 60: 1-20.

Vollbrecht E, Veit B, Sinha N and Hake S (1991). The developmental gene Knotted-1 is a member of a maize homeobox gene family. Nature 350: 241-243. 